\title{
ESTIMATED EEDI VERSUS CALCULATED EEDI USING S/P TRIALS FOR A CHEMICAL OIL TANKER
}

\author{
Bosoanca Ioan \\ "Dunarea de Jos" University of Galati, \\ Faculty of Naval Architecture, Galati, Domneasca \\ Street, No. 47, 800008, Romania, \\ E-mail: ioan.bosoanca@ugal.ro
}

\begin{abstract}
A cleaner environment to prevent dramatic climate changes is the goal of nowadays. Efforts to achieve this goal in marine field have been made by designers, shipbuilders, stakeholders, charterers and owners. Regarding the latest requirements, in the revised edition of ISO 15016 - 2015, see [2], has been shown the Marine Environment Protection Committee by IMO Resolution MEPC 214 (63) delivered a mandatory Guideline for ships, applied for survey and certification of attained EEDI (Energy Efficiency Design Index) for every new ship. Romanian designers and shipbuilders made special efforts to update this ship to the new rules of MEPC, having the goal to reduce marine pollution even this type of ship is in disadvantage regarding container vessels, where reducing speed is very easy with slow steamer technology. The paper presents the estimation of the attained EEDI onboard a new 40500 dwt Chemical Oil Tanker versus EEDI calculated on the basis of $S / P$ trials.
\end{abstract}

Keywords: Cleaner environment, IMO Resolution, attained EEDI

\section{INTRODUCTION}

The necessity of a cleaner environment by reduction of gases emissions in marine field, has been quantified by a so called attained EEDI (Energy Efficiency Design In$d e x$ ) introduced by Marine Environment Protection Committee (MEPC) by the Resolution 212 (63), according to [1], [3] and [7].

EEDI index being measured in grams $\mathrm{CO}_{2}$ can be considered as $\mathrm{CO}_{2}$ emission (pollution) per cargo transported tone.

Even there are some disputes on the edge of this index, until now is the only tools fully accepted by classification societies, to evaluate the $\mathrm{CO}_{2}$ emission (pollution) onboard ships.
A good thing which happened is the EEDI encouraged the researchers and designers in marine field to use innovative devices and technologies which can save power onboard ships: rudder bulbs, fins (i.e. wellknown PBCF - propeller boss cap fins), ducts and combination of them (i.e. wellknown Mewiss Duct) in front of propeller disk, slow steaming (especially for container vessels), solar power and wind energy there are just some examples.

According to [1] all new ships being greater than 400 gross tonnage must calculate this factor beginning with 2013 and the calculated value of this index shall be under the curve corresponding to Phase 1 (2015 2020), for now on (see Fig. 1). 
Beginning with 2020 all permissive value will be reduced with a supplementary 5 $10 \%$ which means an additional $15-20 \%$ related to phase $0(2013-2015)$. is:

The calculation formula according to [1],

$$
\begin{aligned}
& \frac{\left(\prod_{j=1}^{n} f_{j}\right)\left(\sum_{i=1}^{n M E} P_{M E i} \circ C_{F M E(i)} \circ S F C_{M E(i)}\right)}{f_{i} \circ f_{C} \circ \text { Capacity } \circ f_{w} \circ V_{\text {ref }}} \\
& +\frac{\left(P_{A E} \circ C_{F A E} \circ S F C_{A E}^{*}\right)}{f_{i} \circ f_{C} \circ \text { Capacity } \circ f_{w} \circ V_{r e f}}+ \\
& \frac{\left(\left(\prod_{j=1}^{n} f_{j} \circ \sum_{i=1}^{n P T I} P_{P T I}(i)-\sum_{i=1}^{n e f f} f_{\text {eff }(i)} \circ P_{A E e f f(i)}\right) \circ C_{F}\right.}{f_{i} \circ f_{c} \circ \text { Capacity } \circ f_{w} \circ V_{r e f}} \\
& \frac{-\left(\sum_{i=1}^{n e f f} f_{\text {eff }(i)} \circ P_{\text {eff }(i)} \circ C_{F M E} \circ S F C_{M E}^{* *}\right)}{f_{i} \circ f_{c} \circ \text { Capacity } \circ f_{w} \circ V_{r e f}}
\end{aligned}
$$

where, in accordance with [3]:

$f_{\mathrm{j}}$ : correction factor for ship specific design elements;

$\boldsymbol{P}_{\text {MEi }}$ : power of main engines;

$\boldsymbol{C}_{\mathbf{F}}$ : conversion factor between fuel consumption and $\mathrm{CO}_{2}$ emission;

$S F C$ : specific fuel consumption;

$\boldsymbol{P}_{\text {AEeff }}$ : auxiliary power reduction;

$P_{\text {PTI }}$ : shaft motor power;

$f_{\text {eff }}$ : availability factor of innovative energy efficiency technology;

$\boldsymbol{P}_{\text {AEeff }}$ : auxiliary power reduction;

$f_{\mathrm{i}}$ : capacity factor;

$f_{\mathbf{c}}$ : cubic capacity correction factor;

Capacity: bulk carriers, tankers, gas carriers, ro-ro cargo ships and general cargo ships shall use deadweight as capacity;

$f_{\mathrm{w}}$ : weather factor;

$V_{\text {ref }}$; ship's speed.
EEDI Reduction factor Phase 1

(2015-2020)

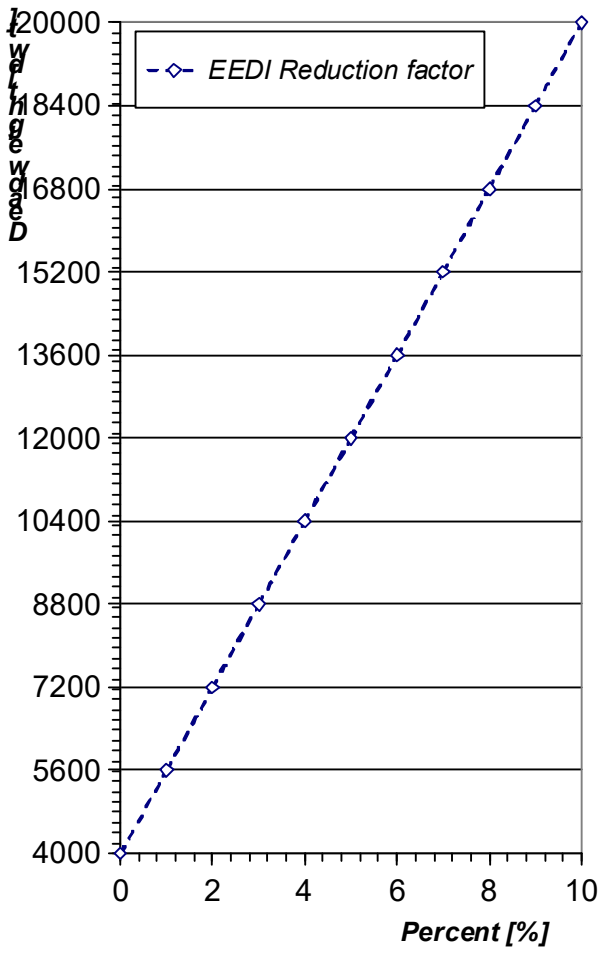

Fig. 1 EEDI Phase 1 (2015 - 2020)

\section{SHIP DATA FOR EEDI CALCULUS \\ MAIN PARTICULARS according to [4]:}

Classification: RINA, see [5], CSR (Common Structural Rules);

\section{Hull:}

- length overall approx.: $\mathbf{1 7 9 . 9 9} \mathrm{m}$;

- length between p.p. approx.: $173.3 \mathrm{~m}$;

- breadth molded approx.: $\mathbf{3 2 . 2 6} \mathrm{m}$;

- depth approx.: 17.0 m;

- design draft: $10.6 \mathrm{~m}$;

- deadweight (max.): $40500 \mathrm{dwt}$. 


\section{Machinery:}

- 1 main engines MAN B\&W having 6480 $\mathrm{kW} / 89 \mathrm{rpm}$ at MCR;

- 3 diesel generators $970 \mathrm{~kW} \mathrm{/} 900 \mathrm{rpm}$ fueled with marine gas oil (MGO);

- 1 FPP with 4 blades at 89 rpm; propeller diameter: $6.50 \mathrm{~m}$.

Even this ship has a rudder bulb, the towing test report, delivered by HSVA Germany, concluded the power savings for the setting with the thickest rudder bulb and divergent hub cap vary from 'no-benefit' at 13 knots to $2.2 \%$ reduced power at 15 knots.

For this reason, no benefit has been taken in account in EEDI calculation. Also, no other energy saving equipment has been found onboard this ship.

The ship's profile is shown in the bellow Fig. 2:

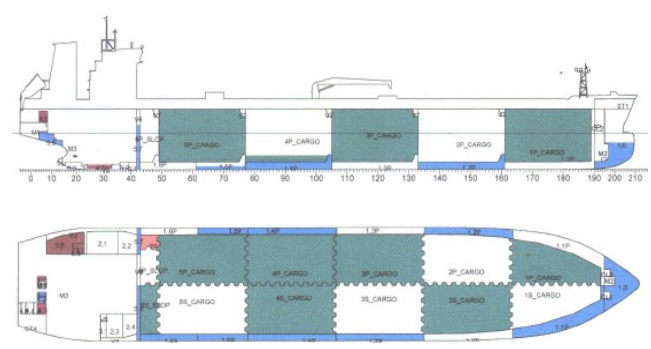

Fig. 2 Ship's profile (up: lateral view; down: upper view) at $T_{F}=T_{A}=10.60 \mathrm{~m}$

Schematic arrangement of propulsion and electric system is shown in Fig. 3:

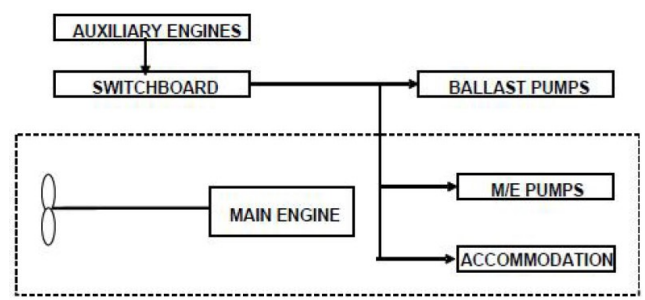

Fig. 3 Schematic figure of propulsion and electric power supply system
In Fig. 4 is shown the location of diesel generators: Platform deck 2 (12800/13700 ABL).

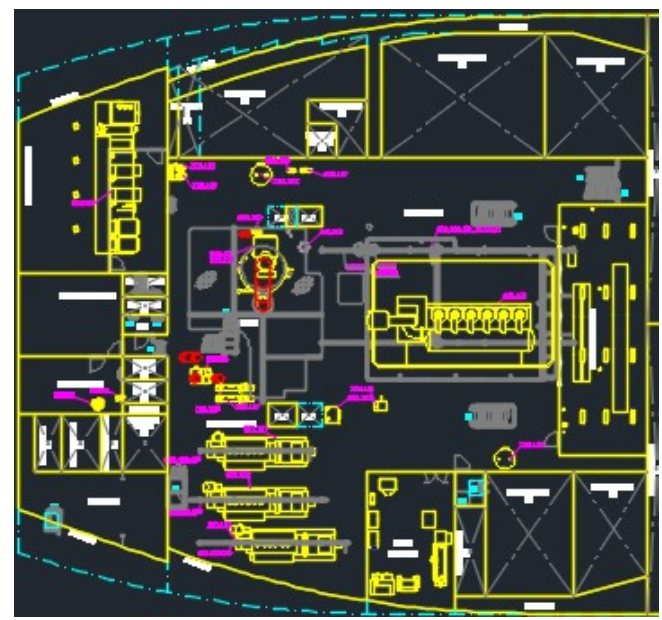

Fig. 4 Platform Deck 2 (12800/13700 ABL)

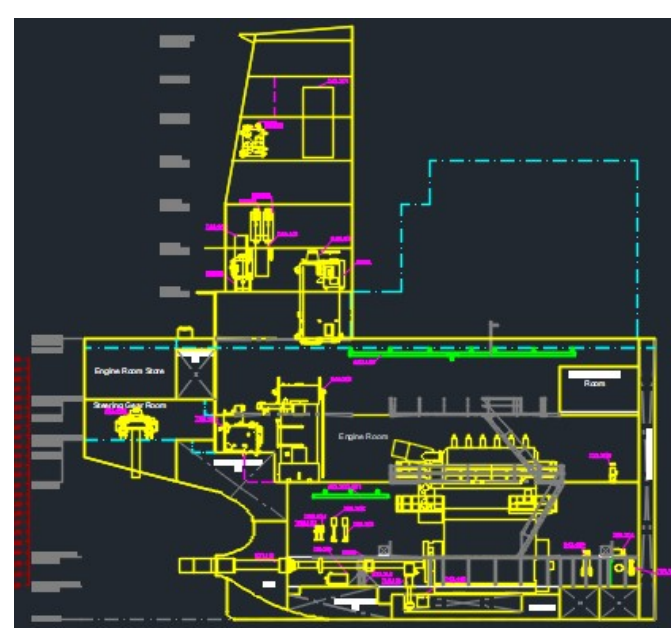

Fig. 5 Side view 


\section{EEDI CALCULUS}

With the above data, the estimated EEDI is according to Fig. 6:

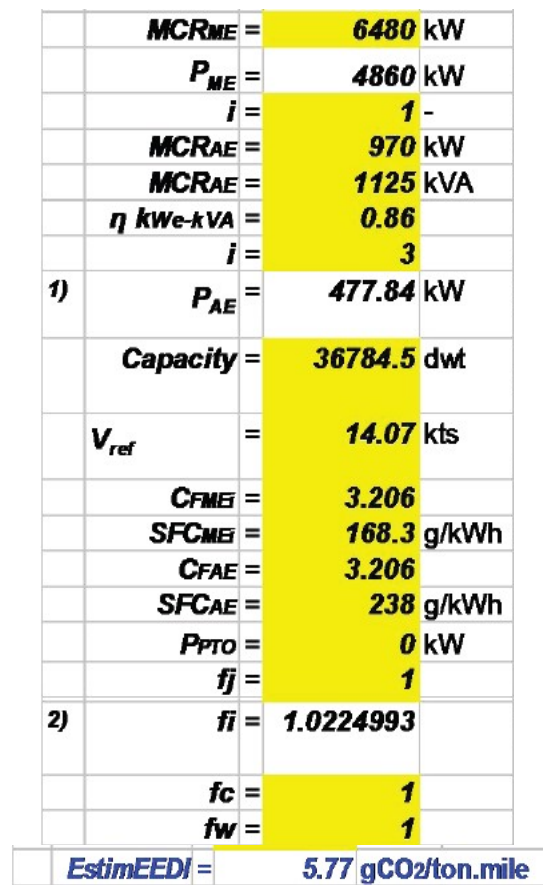

Fig. 6: EEDI Calculus

In this stage of calculus, the deadweight value is taken from Preliminary Stability of this ship. This value shall be compared with Required EEDI, see Fig. 1.

Required EEDI is a maximum permissive value of the attained EEDI for a certain ship's type and tonnage. The required EEDI represents a minimum energy efficiency requirement for new ships related of type and size.

For tankers, the required EEDI is calculated below, see Fig. 7:

\section{REQUIRED EEDI}

RequireEEDI $=$ ReferenceEEDI $=\mathrm{a}^{*} \mathrm{~b}^{-\mathrm{c}}$

\begin{tabular}{|c|c|c|c|}
\hline$a=$ & 1218.8 & & \\
\hline$b=$ & 36785 & & \\
\hline$c=$ & -0.488 & & \\
\hline Required EEDI= & 7.21 & (gCO2ton.mile) & - phase $0(2015-2015)$ \\
\hline Required EEDI= & 6.49 & (gCO2/ton.mile) & - phase 1 (2015 -2020) \\
\hline
\end{tabular}

Fig. 7 Required EEDI

According to Fig. 6, in phase 1, regulation criteria is satisfied with of $11.05 \%$ margin.

The correspondent diagram $\boldsymbol{P}_{\boldsymbol{B}}$ vs. $\boldsymbol{V}_{\boldsymbol{S}}$ (Power in [kW] - ship's speed in [kts]) is shown in the below Fig. 8:

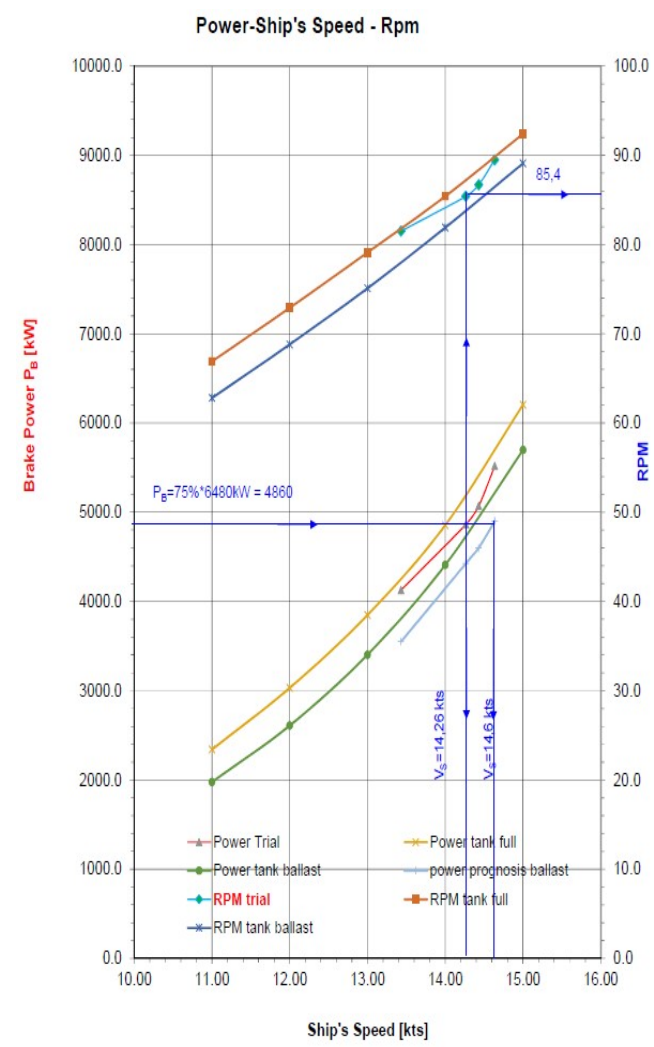

Fig. 8: The diagram $\boldsymbol{P}_{\boldsymbol{B}}-\boldsymbol{V}_{\boldsymbol{S}}-\boldsymbol{R} \boldsymbol{p m}$ recorded in $S / P$ trials 


\section{S/P TRIALS}

Sea trials of this ship have been conducted in the following manner, according to [4] and [7]:

- One double run, bellow EEDI M/E setting;

- Two double runs at EEDI M/E setting;

- $\quad$ One double run, at contractual M/E setting for contractual speed.

The calculated value on basis of $\mathrm{S} / \mathrm{P}$ trials is shown in the below Fig. 9:

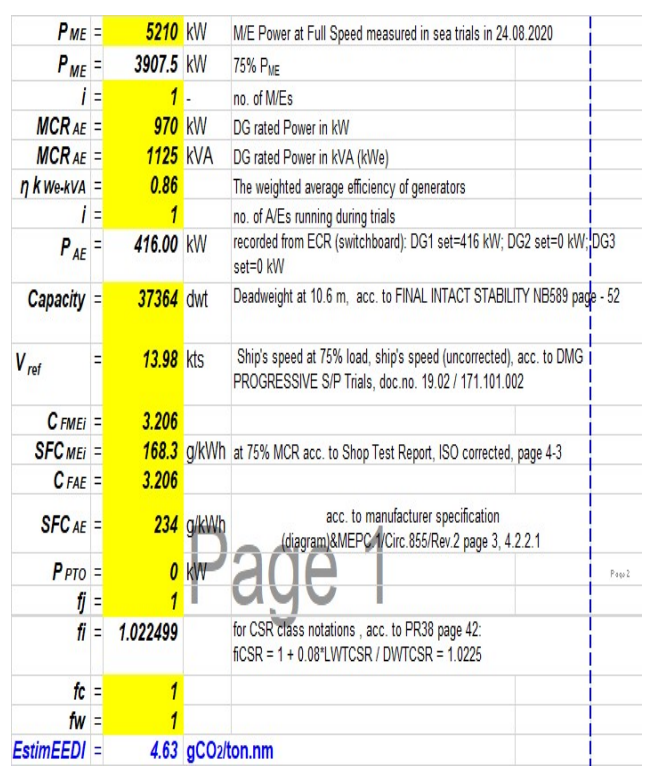

Fig. 9: Calculated EEDI on basis of the results measured in $S / P$ trials acc. to [6]

Calculated EEDI on basis of $\mathrm{S} / \mathrm{P}$ trials according to Fig. 9, is $\mathbf{5 . 1 7} \mathrm{gCO}_{2} /$ ton.nm, better than EEDI calculated in Fig. 6, 5.77 $\mathrm{gCO}_{2}$ /ton.nm.

\section{CONCLUDING REMARKS}

Day by day the legislation on sea and ports related to pollution, is continuously updated having the goal to reduce the emissions, and to avoid climate changes.

(C) Galati University Press, 2020
A ship with a small pollution degree (small EEDI) can has access in any harbor, even in the harbors which are inside an ECA (Emission Control Area) with a very small accepted degree of pollution; for a certain ship this means better opportunities to find cargo, so to be more profitable.

The EEDI calculus is an important stage when the ship is delivered to owner, with a special attention not only of owner but class surveyors also. A clear procedure to perform this task onboard during $\mathrm{S} / \mathrm{P}$ trials of ship assures accuracy results and reliable data necessary in the later analysis and syntheses. Based on them, the legislation in marine field can be updated and improved which finally means a cleaner environment.

For this ship, the S/P trials demonstrated a better EEDI index which means an important advantage not only for shipbuilder but also for ship's owner and, with a $11.9 \%$ margin, satisfying the regulation criteria for the next phase 2 (between 2020 - 2025).

Even so, what is the next step to obtain a smaller EEDI in the years to come? One way to decrease the EEDI in order to fulfill the pollution limits is to apply innovative technologies:

Passive devices, regularly in front of propeller disk: PBCF (Propeller Boss Cap Fin), SILD (Sumitomo Integrated Lammeren Duct), PSS (DSME - Pre Swirl System), Mewis Duct etc... These devices use:

a) fins to generate of a pre-rotation before propeller disk,

b) have a duct ahead the propeller disk for direct flow to the inner radii,

c) generate pre-swirl mainly inwards: reduction of hub vortex losses.

Regarding the efficiency of the Mewis Duct, investigations performed by author, see [8], onboard crude oil tanker of $165000 \mathrm{dwt}$, proved in sea trials a reduction of consumed power at shaft, in ballast conditions, of $3 \%$.

- PTI/PTO generators: N/A for this configuration of the actual shaft line 
due to variable revolution speed of $\mathrm{M} / \mathrm{E}$;

- Low steam engine;

- Dual fuel technologies;

- Fuel cell technologies etc...

These will be a challenge for marine designers in the next 10-20 years which will have the difficult task to updating and implementing these innovative technologies in shipbuilding.

\section{Acknowledgements}

The research has been supported by the $R e$ search Department of Diagnose and Measurements Group Galati, inside the partnership with CONSTANTZA SHIPYARD SA.

The author thanks to Mr. Radu RUSEN and Mr. Marius CORNEA from CONSTANTZA SHIPYARD SA, which made possible this research, onboard vessels $\mathrm{M} / \mathrm{T}$ HISTRIA ATLAS.

\section{REFERENCES}

[1]. RESOLUTION MEPC.212(63) Adopted On 2 March 2012 - GUIDELINES ON THE METHOD OF CALCULATION OF THE ATTAINED ENERGY EFFICIENCY DESIGN INDEX (EEDI) FOR NEW SHIPS
[2]. ISO 15016-2015 SHIPS AND MARINE TECHNOLOGY -- GUIDELINES FOR THE ASSESSMENT OF SPEED AND POWER PERFORMANCE BY ANALYSIS OF SPEED TRIAL DATA

[3]. BOSOANCA I., METHODS TO REDUCE GAS EMISSIONS ONBOARD SHIPS - THE ANNALS OF "DUNAREA DE JOS" UNIVERSITY OF GALATI FASCICLE XI SHIPBUILDING. ISSN 1221-4620, 2017

[4]. ***DMG Galati Ltd., EEDI (Energy efficiency Design Index) PROCEDURE Chemical / Oil Tanker 40500 dwt, Galati- 2019;

[5]. ***RINA - RULES FOR CLASSIFICATION OF Ships 2018, https://www.rina.org/en/rules; [6]. ***DMG Galati Ltd., Progressive SPEED / POWER Trials Chemical / Oil Tanker 40500 dwt, Dwg. no. 19.02 / 171.101.001, Galati-2019;

[7]. ITTC RECCOMMENDED PROCEDURE AND GUIDELINES 75-04-01-011 Revision 05, Preparation, Conduct and Analysis of Speed / Power Trials, 2017;

[8]. BOSOANCA I., PIRVULESCU Roman, BOSOANCA Radu, EXPERIMENTAL RESEARCHES REGARDING POWER SAVING USING NOVEL ADDITIONAL SYSTEM FOR SHIPS WITH FULL FORMS - THE ANNALS OF "DUNAREA DE JOS" UNIVERSITY OF GALATI FASCICLE XI - SHIPBUILDING. ISSN 1221-4620, 2013.

Paper received on March $21^{\text {th }}, 2020$ 